\title{
Clinical Outcome of Percutaneous Endoscopic Lumbar Surgery (PELS) in Treatment of Lumbar Disc Herniation
}

\author{
Mangal P. Hirachan, Zengxin Gao*, Yucheng Lin, Ratish Singh \\ Department of Spine Surgery, Zhongda Hospital Affiliated to Southeast University, Nanjing, China \\ Email: ${ }^{5} 52366015 @ q q . c o m$
}

How to cite this paper: Hirachan, M.P., Gao, Z.X., Lin, Y.C. and Singh, R. (2017) Clinical Outcome of Percutaneous Endoscopic Lumbar Surgery (PELS) in Treatment of Lumbar Disc Herniation. Open Journal of Orthopedics, 7, 99-109.

https://doi.org/10.4236/ojo.2017.74012

Received: March 22, 2017

Accepted: April 25, 2017

Published: April 28, 2017

Copyright ( 92017 by authors and Scientific Research Publishing Inc. This work is licensed under the Creative Commons Attribution International License (CC BY 4.0). http://creativecommons.org/licenses/by/4.0/

\begin{abstract}
Lumbar disc herniation is a spinal problem seen in both young and old people causing pain in the back with pain and numbness in lower extremity leading to disability limiting daily activities. When conservative treatments are ineffective, then it is treated by surgeries, more recently with minimal invasive percutaneous endoscopic lumbar surgery (PELS). One of the mostly accepted PELS by spinal surgeons is percutaneous transforaminal endoscopic lumbar discectomy, which can be performed for any age. The main aim of this review was to evaluate clinical outcome and safety based on the Oswestry Disable Index (ODI), Visual Analog Scale (VAS) and MacNab criteria and complications of PELS surgery and its advantages in clinical basis.
\end{abstract}

\section{Keywords}

Lumbar Disc Herniation (LDH), Percutaneous Endoscopic Lumbar Surgery (PELD), Percutaneous Transforaminal Endoscopic Lumbar Discectomy (PTELD), Interlaminar Percutaneous Endoscopic Lumbar Discectomy (ILPELD)

\section{Introduction}

Lumbar disc herniation is one of the common causes of low back pain with sciatica in young and adult with huge economic burden to family and society [1] [2] [3]. Point prevalence of lumber disc herniation is $37.1 \%$, 1-year prevalence of $76.0 \%$, and lifetime prevalence of $85.5 \%$ [4]. About $70 \%-80 \%$ of population experiences back pain in lifetime. It's reported that the prevalence of herniated discs are higher among people 35 - 45 years old [5]. Not all herniated disc need operative treatment but when sign and symptoms such as back with or without radicular leg pain progressively increase despite of conservative treatment for more than 6 weeks, neurological deficits as foot drop, cauda equine, etc. are seen 
then has to undergo for surgery. Currently, there are numerous surgical interventions for lumber disc herniation. They can be broadly classified as posterior open discectomies and percutaneous techniques. Posterior open discectomies include open laminectomy and discectomy, micro discectomy, micro endoscopic discectomy, hemi laminectomy with discectomy, among which micro discectomy remains the standard surgery for lumber disc herniation. Whereas, percutaneous techniques include chemonucleolysis, nucleoplasty, intradiscal electrothermal therapy, percutaneous laser discectomy and percutaneous endoscopic lumbar surgery (PELS) [6] [7] [8]. Except PELS, all of the percutaneous techniques are blind procedure, whereas, PELS is performed under direct endoscopic vision.

Percutaneous endoscopic lumbar surgery is one of the latest emerging techniques in treatment of lumbar disc herniation. Kambin and Gellman in 1973 and Hijikatain 1975 first introduced non-visualized percutaneous central nucleotomy via posterolateral approach [9] [10]. After introduction of direct visualization of intervertebral disc space with modified arthroscopy by Forest and Housman in 1983, this technique has been widely practiced for treatment of lumber disc herniation [7]. In 1992 Kambin P. further defined removal of protruded disc passing through Kambin's triangle, considered to be a safe site in posterolateral region [11]. Recently, there are 2 techniques widely used for percutaneous endoscopic surgery: 1) transforaminal approach described by Yeung (Yeung Endoscopic spinal surgery, YESS) in 1997 and Hoogland (Transforaminal endoscopic spine surgery system, TESSYS) in 1994 [12] [13]; 2) Interlaminar approach described by Ruetten in 2008 [14]. The indications for transforaminal endoscopic treatment are the same as classical discectomy procedures. Now due to advancement of instrumentation and skill of surgeon indication has broadened.

\section{Surgical Technique}

If the surgery is indicative then all pre-operation evaluation and preparation are performed; this surgery can be done in two positions; prone or lateral decubitus position. If the patient is placed in prone position then hip and knee are flexed and pillow is placed between lower abdominal and chest so that abdomen is hanged freely. For lateral decubitus position, pillow is placed under the waist, which will open up the foramen and allow the Dura to fall down to the contra-lateral side avoiding damage on introduction of the cannula and the also reduced intra-abdominal pressure and decrease bleeding. Then under guidance of $\mathrm{C}$-arm, entry point is marked $8-16 \mathrm{~cm}$ from midline of vertebra to lateral side according to the disc interval at an angle of $15-25$ degrees in horizontal plane [15] [16]. Under all aseptic condition and local anesthesia (1\%lidocane), and under anteroposterior (AP) and lateral view, a $25 \mathrm{~cm} 18$ gauge needle is inserted in the level of herniated disc through the posterolateral approach. Intraoperative discogram is then performed with a $2 \mathrm{~mL}$ mixture of contrast medium and methylene blue at the ratio of 9:1 and help of c-arm. If the dye is seen in the epidur- 
al space nucleus then it indicates the herniated fragment. Then guide wire is inserted and the needle is removed leaving the guide wire in situ. A small skin incision of $8 \mathrm{~mm}$ is then given over the guide wire entry point. A $2 \mathrm{~mm}$ conical rod is introduced over the guiding wire, and then sequentially the first, second and third sleeves were inserted dilating the soft tissues up to $6.5 \mathrm{~mm}$. Then the reamer is introduced anti clockwise, to avoid damage to the spinal muscles and continuously under the guidance of image intensifier reamed to 1 or $2 \mathrm{~mm}$ inside the medial pedicular line. The procedure is repeated with each of the sequentially larger rods, tubes and reamers. Then working cannula is introduced over the third conical rod and its tip should be located on the herniated disc. Then image intensifier is removed and working endoscope set introduced and herniated disc is removed under direct visualization as in Figure 1. After complete decompression, the dural sac and the lumber exiting nerve root is checked for freely movable with the valsalva maneuver. Bleeding of the small vessels is controlled with a flexible bipolar radio frequency probe. Communication with patients is maintained throughout the procedure. Though the technique is considered to be much safer but it involves several technical challenges, such as the critical narrow access through the foraminal triangular window and the limited intradiscal and epidural working space.

\section{Discussion}

In recent time, percutaneous endoscopic lumbar surgery specially transforaminal approach is widely used to treat lumber disc herniation due to its comparable significant outcome as shown in Table 1. This transforaminal approach can be approached by two techniques YESS and TYSSYS. The standard indication for percutaneous transforaminal endoscopic lumber discectomy (PTELD) is limited to soft (non calcified) and contained $\mathrm{LDH}$, which caused discogenic leg pain that
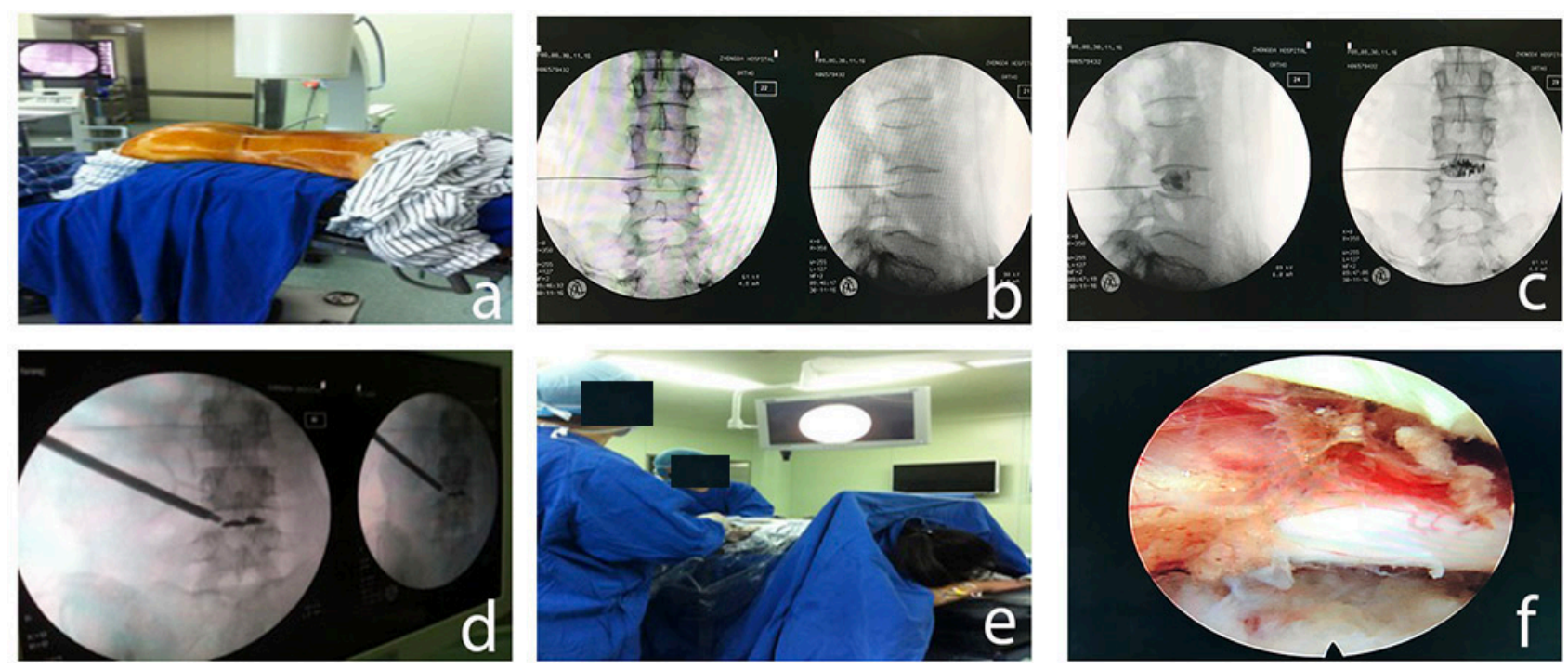

Figure 1. Procedure for percutaneous endoscopic lumbar surgery. (a) positioning of patient in operating table, (b) Insertion of 25 $\mathrm{cm}$ 18-gauge needle, (c) discogram with mixture of contrast medium and methylene blue, (d) reaming over dilator, (e) removal of content under direct vision with endoscope and (f) free nerve root after discectomy. 


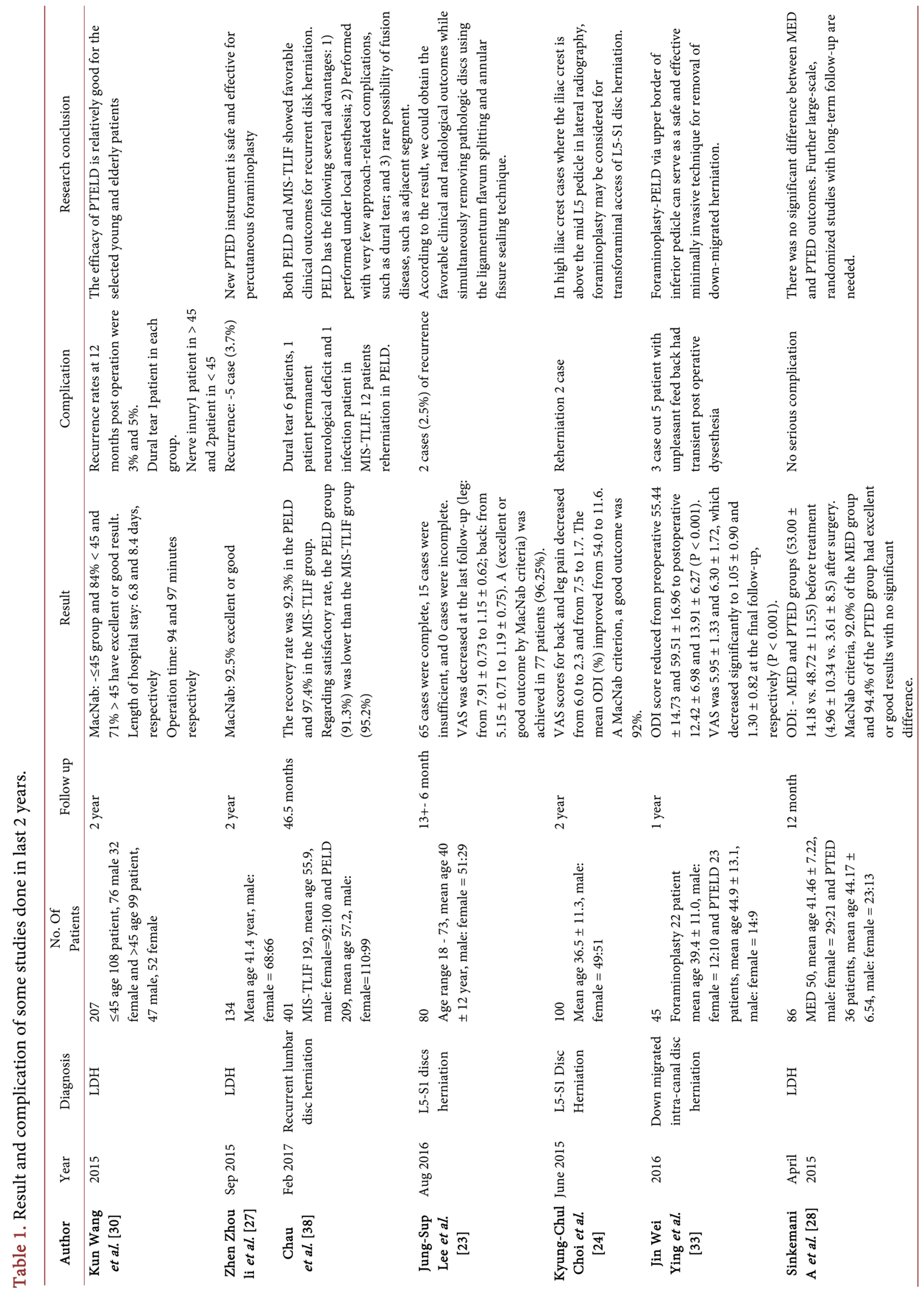


didn't respond to respond to any conservative treatment. But In the hands of an experienced operator, PTELD is also indicated for most spectrums of LDH, except for calcified discs or sequestration discs which are separate and migrating from the disc space. The continuity of the hernia with the disc space but not its size is the key determinant of the indications for PTELD. Sang Soo Eun et.al in 2016 performed PTELD among 38 patients which showed favorable long term outcome of PTELD [17]. Another study by Zhimin Pan et al. in China in 2015 showed TYSSYS was well tolerated by 106 patients studied and entailed less trauma and quick recovery [18]. The clinical outcome of these techniques is basically evaluated by Oswestry Disable Index (ODI 0\% - 100\%) [19] based on daily activities of the patient, Visual Analogue Scale (VAS, 0 - 10) [20] for pain severity and $\mathrm{MacNab}$ criteria [21] for therapeutic evaluation.

\subsection{Clinical Outcome Evaluated by ODI, VAS and MacNab Criteria}

A MacNab criterion is evaluated in four ratings as per their symptomatic relief; excellent, good, fair and poor. (Excellent: no pain, no restriction of mobility, return to normal work and level of activity; Good: occasional non radicular pain, relief of presenting symptoms, able to return to modified work; Fair: some improved functional capacity, still handicapped and/or unemployed; Poor: continued objective symptoms of root involvement, additional operative intervention needed at the index level irrespective of the length of postoperative follow-up). Based on the modified MacNab criteria, study done in Taiwan showed $89 \%$ of patients achieved excellent (28\%) or good (61\%) outcomes after surgery [22]. Similarly, other studies till date showed good outcome 80\% - 96.7\% after PTELD surgery [14] [23]-[29]. The studies have shown that the most of the patients after PELS had the 'good' outcome on the basis of MacNab criteria. A Study done by Kun Wang et al. also indicated that outcome based on MacNab criteria can be different based on age as they found out that outcome in the age $\leq 45$ group were better than the age $>45$ group $(p=0.03)$ [30]. Few other studies also found better result based on MacNab criteria in younger patients than old ones [16]. PTELD was also able to get $75.77 \%-81.4 \%$ excellent or good outcome on basis of MacNab criteria even for recurrent disc herniation [29] [31] [32].

ODI is another factor to determine the clinical efficacy of treatment related to spine problems. This is indexed based on the symptomatic relief of leg and back pain after the treatment. In PELS, many studies have used to evaluate the outcome and found that the value of ODI is remarkably decreased after this surgery. Kyung Chui et al. found out that the mean ODI (\%) improved from 54.0 to 11.6 among 100 patients after PELS [24]. Another study done in two groups showed the mean ODI score reduced from preoperative $55.44 \pm 14.73$ and $59.51 \pm 16.96$ to postoperative $12.42 \pm 6.98$ and $13.91 \pm 6.27$ respectively $(\mathrm{P}<0.001)$ [33]. Another two studies compared the outcome based on age and sex of the patients, which showed no difference in ODI [16] [30], VAS was also seen significantly improved after PELS, which is evaluated, based on the symptomatic relief. Prospective Study done by Pravesh S. gadjradj et al. in $167 \mathrm{LDH}$ who underwent 
PELS, The mean VAS score for leg pain was $82.5 \mathrm{~mm}$ (range 5 - $100 \mathrm{~mm}$ ), Six weeks after the surgery, the scores on the VAS was found to be significantly reduced $(\mathrm{p}<0.001)$, which was progressively reduced after 52 weeks of follow up [25]. Another study by Kyung Chui et al. found significant improvement in VAS of leg and back pain from 7.5 to 1.7 and from 6.0 to 2.3 [24]. Another study performed in two groups found that the mean preoperative VAS was $5.95 \pm 1.33$ and $6.30 \pm 1.72$, which decreased significantly to $1.05 \pm 0.90$ and $1.30 \pm 0.82$ at the final follow-up, respectively $(\mathrm{P}<0.001)$ [33]. The improvement in VAS score didn't have any significance based on age, which was found in studies that compared age and sex of the patients showed no difference in VAS score [16] [30].

\subsection{Complication}

Despite many researches till date have discussed about the clinical efficacy of PELS and its wide, certainly some complications of the surgeries have also been reported such as Dural tear, hematoma collection, residual disc specimen, vascular injury, infection, thrombophlebitis, etc. [34]. During the procedure there is also potential risk of damaging the nerve roots as they are in close proximity to the intra foraminal disc space [35] [36]. 1\% - 2\% cases of nerve injury have been seen in some reported studies [30]. Different studies till date studies have showed the reherniation rate of 3 - 6.6 [14] [16] [25] [27] [29]. A study in China reported one patient experienced recurrent LDH 4 months after surgery. Moreover, eight patients (6\%) sustained temporary dysesthesia over the proximal lower limb of the operated side during the early days of the surgery [22]. Study by Wang Cheng et al. study showed $5.9 \%$ postoperative dysesthesia. However, There has not yet been a report of any intra-canal or foraminal adhesions following the procedure in the literature [18]. Though few complications have been seen post procedure but literatures have reported the complication rate to be very low. S0, we still believe this technique is safe to be performed for the treatment of the patients.

\subsection{Comparison of PELS and Other Techniques}

Since the advancement in spinal surgery, various techniques have been developed to treat the spinal problems. Especially in recent years, minimally invasive procedures are overtaking open surgeries because of their extensive benefit. Various Studies have been done to see outcome of percutaneous endoscopic surgery, between PTELD and MED, PTELD and open lumbar discectomy, etc. A randomized trial done by lei pan et al. between open lumber discectomy and PTELD showed MacNab satisfaction of above $90 \%$ in both groups after surgery while no significant difference noted in pain index $(p>0.05)$ [34]. Sand-soak Ahn et al. showed significant difference in vas score of back pain at 6-month 12 month $\mathrm{P}<0.001, \mathrm{P}=0.012$ respectively but no significant difference in VAS score of leg pain $\mathrm{p}=0.553,0.259$ respectively in open lumbar discectomy (OLD) and PELS groups after surgery [16]. The comparative studies indicated that the both OLD and PES are similar in clinical efficacy in pain relief whereas Dong 
Yeob Lee et al. showed less rate of complication 4\% in PES compare to $10.3 \%$ in OLD [31]. Comparative Study by Lei Pan et al. found PTES has less hospital stays $1.9 \pm 0.74$ days compared to OLD $5.6 \pm 1.26$ respectively. Due to the statistically significant difference in CRP, CPK and IL- 6 between the two groups, the PELD had less tissue damages to the human body than OLD surgery [34]. In addition, the patients underwent PELD had less recovery time and shorter hospital stay and early return to work compared to the patients treated with OLD. The clinical outcome of PELD based on MacNab criteria was better than the open lumbar discectomy whereas both the surgeries were seemed similar in alleviating the pain index of the patients.

Several comparisons have also been done between another two minimally invasive techniques, PTED and MED. The clinical outcome according to MacNab criteria was found to be mixed, Sinkemani et al. showed $92.0 \%$ of the MED group and $94.4 \%$ of the PTED group had excellent or good results according to MacNab criteria with no significant difference [28]. Whereas Liuwen Gui et al. showed $75.96 \%$ in the PELD group and $84.15 \%$ in the MED group achieved excellent or good results respectively, which was statistically significant ( $p=$ 0.0402). However, the hospitalization duration of the MED group was 11.6 days, significantly longer than that of the PLD group (7.9 days, $\mathrm{P}<0.01$ ), and the mean cost of the MED group was, significantly higher than that of the PELD group (P < 0.01) [37]. Chao Liu et al. in 2016 compared PELD and Minimally Invasive Transforaminal Lumbar Interbody Fusion for Recurrent Lumbar Disk Herniation; the recovery rate was $92.3 \%$ in the PELD and $97.4 \%$ in the MIS-TLIF group. During the follow-up period, postoperative data between both groups showed no significant differences in the mean total postoperative VAS score for leg pain, and ODI score [38]. The PELD was found to have lesser hospital stay days than open surgery and other percutaneous surgeries, low cost study done by Ruetten et al. [14], very less blood loss [39], early return to work, and minimal scar and tissue damage [34]. Kyung-Chul Choi et al. compared transforaminal PELD (TF-PELD) and interlaminar PELD (IL-PELD) both of which are the types of percutaneous surgeries; a significant difference between groups was demonstrated in terms of disc type, location, and migration. TF-PELD was preferred for shoulder type, centrally located, and recurrent disc herniation, while IL-PELD was preferred for axillary type and migrated discs, especially those of a high grade [24].

\section{Conclusion}

PTED can be an alternative technique in spine surgery. The clinical outcome is very satisfactory for the treatment of lumber disc herniation which was similar to other surgeries, but the short hospital stay, minimal blood loss and low cost than other open surgeries and even than other percutaneous surgeries such as MED are some of the benefits of PTED over them. The clinical outcome on the basis of MacNab criteria, ODI and VAS all showed significant clinical improvement post PTELD. The clinical TF-PELD was preferred for shoulder type, cen- 
trally located, and recurrent disc herniation. Few complications like reherniation and dysesthesia could occur post surgery but was found to be very low thus implying the safety of the procedure. Therefore, wide acceptance of this procedure is increasing more all over the world. Further studies with long-term follow up should be performed on the percutaneous surgeries to enhance the use of this surgery.

\section{Conflict of Interest}

None.

\section{References}

[1] Dewing, C.B., et al. (2008) The Outcomes of Lumbar Microdiscectomy in a Young, Active Population: Correlation by Herniation Type and Level. Spine, 33, 33-38. https://doi.org/10.1097/BRS.0b013e31815e3a42

[2] Maetzel, A. and Li, L. (2002) The Economic Burden of Low Back Pain: A Review of Studies Published between 1996 and 2001. Best Practice \& Research: Clinical Rheumatology, 16, 23-30. https://doi.org/10.1053/berh.2001.0204

[3] Dagenais, S., Caro, J. and Haldeman, S. (2008) A Systematic Review of Low Back Pain Cost of Illness Studies in the United States and Internationally. The Spine Journal, 8, 8-20. https://doi.org/10.1016/j.spinee.2007.10.005

[4] Schmidt, C.O., et al. (2007) Back Pain in the German Adult Population: Prevalence, Severity, and Sociodemographic Correlates in a Multiregional Survey. Spine, 32, 2005-2011. https://doi.org/10.1097/BRS.0b013e318133fad8

[5] Heliovaara, M. (1987) Occupation and Risk of Herniated Lumbar Intervertebral Disc or Sciatica Leading to Hospitalization. Journal of Chronic Diseases, 40, 259 264.

[6] Mixter, W.J. and Ayer, J.B. (1935) Herniation or Rupture of the Intervertebral Disc into the Spinal Canal-Report of Thirty-Four Cases. The New England Journal of Medicine, 213, 385-393. https://doi.org/10.1056/NEJM193508292130901

[7] Forst, R. and Hausmann, B. (1983) Nucleoscopy-A New Examination Technique. Archives of Orthopaedic and Trauma Surgery, 101, 219-221. https://doi.org/10.1007/BF00436774

[8] Smith, L. (1964) Enzyme Dissolution of the Nucleus Pulposus in Humans. JAMA, 187, 137-140. https://doi.org/10.1001/jama.1964.03060150061016

[9] Hijikata, S. (1989) Percutaneous Nucleotomy. A New Concept Technique and 12 Years' Experience. Clinical Orthopaedics and Related Research, No. 238, 9-23. https://doi.org/10.1097/00003086-198901000-00003

[10] Kambin, P. and Gellman, H. (1983) Percutaneous Lateral Discectomy of the Lumbar Spine. A Preliminary Report. Clinical Orthopaedics and Related Research, 174, 127-132.

[11] Kambin, P. (1992) Arthroscopic Microdiscectomy. Arthroscopy. The Journal of Arthroscopic \& Related Surgery, 8, 287-295. https://doi.org/10.1016/0749-8063(92)90058-J

[12] Yeung, A.T. and Tsou, P.M. (2002) Posterolateral Endoscopic Excision for Lumbar Disc Herniation: Surgical Technique, Outcome, and Complications in 307 Consecutive Cases. Spine, 27, 722-731. https://doi.org/10.1097/00007632-200204010-00009

[13] Hoogland, T., et al. (2006) Transforaminal Posterolateral Endoscopic Discectomy 
with or without the Combination of a Low-Dose Chymopapain: A Prospective Randomized Study in 280 Consecutive Cases. Spine, 31, E890-E897. https://doi.org/10.1097/01.brs.0000245955.22358.3a

[14] Ruetten, S., Komp, M., Merk, H. and Godolias, G. (2008) Full-Endoscopic Interlaminar and Transforaminal Lumbar Discectomy versus Conventional Microsurgical Technique: A Prospective, Randomized, Controlled Study. Spine, 33, 931-939. https://doi.org/10.1097/BRS.0b013e31816c8af7

[15] Liao, Z., Chen, W. and Wang, C.H. (2014) Transforaminal Percutaneous Endoscopic Surgery for Far Lateral Lumbar Intervertebral Disk Herniation. Orthopedics, 37, e717-e727. https://doi.org/10.3928/01477447-20140728-58

[16] Ahn, S.-S., Kim, S.-H., Kim, D.-W. and Lee, B.-H. (2016) Comparison of Outcomes of Percutaneous Endoscopic Lumbar Discectomy and Open Lumbar Microdiscectomy for Young Adults: A Retrospective Matched Cohort Study. World Neurosurgery, 86, 250-258. https://doi.org/10.1016/j.wneu.2015.09.047

[17] Eun, S.S., Lee, S.H. and Sabal, L.A. (2016) Long-Term Follow-Up Results of Percutaneous Endoscopic Lumbar Discectomy. Pain Physician, 19, E1161.

[18] Pan, Z., Ha, Y., Yi, S. and Cao, K. (2016) Efficacy of Transforaminal Endoscopic Spine System (TESSYS) Technique in Treating Lumbar Disc Herniation. Medical Science Monitor, 22, 530-539. https://doi.org/10.12659/MSM.894870

[19] Fairbank, J.C.T. and Pynsent, P.B. (2000) The Oswestry Disability Index. Spine, 25, 2940-2953. https://doi.org/10.1097/00007632-200011150-00017

[20] McCaffery, M. and Pasero, C. (2001) Using the 0-to-10 Pain Rating Scale: Nine Common Problems Solved. The American Journal of Nursing, 101, 81-82. https://doi.org/10.1097/00000446-200110000-00031

[21] Ahn, Y., Lee, S.H., Chung, S.E., Park, H.S. and Shin, S.W. (2005) Percutaneous Endoscopic Cervical Discectomy for Discogenic Cervical Headache Due to Soft Disc Herniation. Neuroradiology, 47, 924-930. https://doi.org/10.1007/s00234-005-1436-y

[22] Tzaan, W. (2007) Transforaminal Percutaneous Endoscopic Lumbar Discectomy. Chang Gung Medical Journal, 30, 226.

[23] Lee, J.-S., Kim, H.-S., Jang, J.-S. and Jang, I.-T. (2016) Structural Preservation Percutaneous Endoscopic Lumbar Interlaminar Discectomy for L5-S1 Herniated Nucleus Pulposus. BioMed Research International, 2016, Article ID: 6250247. https://doi.org/10.1155/2016/6250247

[24] Choi, K.-C. and Park, C.-K. (2016) Percutaneous Endoscopic Lumbar Discectomy for L5-S1 Disc Herniation: Consideration of the Relation between the Iliac Crest and L5-S1 Disc. Pain Physician, 19, E301-E308.

[25] Gadjradj, P.S., et al. (2016) Clinical Outcomes after Percutaneous Transforaminal Endoscopic Discectomy for Lumbar Disc Herniation: A Prospective Case Series. Neurosurgical Focus, 40, E3. https://doi.org/10.3171/2015.10.FOCUS15484

[26] Lee, S.-H., et al. (2006) Comparative Radiologic Evaluation of Percutaneous Endoscopic Lumbar Discectomy and Open Microdiscectomy: A Matched Cohort Analysis. The Mount Sinai Journal of Medicine, 73, 795-801.

[27] Li, Z.-Z., Hou, S.-X., Shang, W.-L., Cao, Z. and Zhao, H.-L. (2016) Percutaneous Lumbar Foraminoplasty and Percutaneous Endoscopic Lumbar Decompression for Lateral Recess Stenosis through Transforaminal Approach: Technique Notes and 2 Years Follow-Up. Clinical Neurology and Neurosurgery, 143, 90-94. https://doi.org/10.1016/j.clineuro.2016.02.008

[28] Sinkemani, A., et al. (2015) Outcomes of Microendoscopic Discectomy and Percu- 
taneous Transforaminal Endoscopic Discectomy for the Treatment of Lumbar Disc Herniation: A Comparative Retrospective Study. Asian Spine Journal, 9, 833-840. https://doi.org/10.4184/asj.2015.9.6.833

[29] Ahn, Y., et al. (2004) Percutaneous Endoscopic Lumbar Discectomy for Recurrent Disc Herniation: Surgical Technique, Outcome, and Prognostic Factors of 43 Consecutive Cases. Spine, 29, E326-E332. https://doi.org/10.1097/01.brs.0000134591.32462.98

[30] Wang, K., et al. (2015) Evaluation of Transforaminal Endoscopic Lumbar Discectomy in the Treatment of Lumbar Disc Herniation. International Orthopaedics, 39, 1599-1604. https://doi.org/10.1007/s00264-015-2747-1

[31] Lee, D.Y., Shim, C.S., Ahn, Y., Choi, Y.G., Kim, H.J. and Lee, S.H. (2009) Comparison of Percutaneous Endoscopic Lumbar Discectomy and Open Lumbar Microdiscectomy for Recurrent Disc Herniation. Journal of Korean Neurosurgical Society, 46, 515-521. https://doi.org/10.3340/jkns.2009.46.6.515

[32] Li, X., et al. (2016) Percutaneous Endoscopic Lumbar Discectomy for Recurrent Lumbar Disc Herniation. International Journal of Surgery, 27, 8-16. https://doi.org/10.1016/j.ijsu.2016.01.034

[33] Ying, J., et al. (2016) The Effect and Feasibility Study of Transforaminal Percutaneous Endoscopic Lumbar Discectomy via Superior Border of Inferior Pedicle Approach for Down-Migrated Intracanal Disc Herniations. Medicine, 95, e2899.

[34] Pan, L., Zhang, P. and Yin, Q. (2014) Comparison of Tissue Damages Caused by Endoscopic Lumbar Discectomy and Traditional Lumbar Discectomy: A Randomised Controlled Trial. International Journal of Surgery, 12, 534-537.

https://doi.org/10.1016/j.ijsu.2014.02.015

[35] Arslan, M., et al. (2012) Nerve Root to Lumbar Disc Relationships at the Intervertebral Foramen from a Surgical Viewpoint: An Anatomical Study. Clinical Anatomy, 25, 218-223. https://doi.org/10.1002/ca.21213

[36] Torun, F., Dolgun, H., Tuna, H., Attar, A., Uz, A. and Erdem, A. (2006) Morphometric Analysis of the Roots and Neural Foramina of the Lumbar Vertebrae. Surgical Neurology, 66, 148-151. https://doi.org/10.1016/j.surneu.2006.02.041

[37] Liu, W.G., et al. (2009) Long-Term Outcomes of Percutaneous Lumbar Discectomy and Microendoscopic Discectomy for Lumbar Disc Herniation. National Medical Journal of China, 89, 750-753.

[38] Liu, C. and Zhou, Y. (2017) Percutaneous Endoscopic Lumbar Diskectomy and Minimally Invasive Transforaminal Lumbar Interbody Fusion for Recurrent Lumbar Disk Herniation. World Neurosurgery, 98, 14-20. https://doi.org/10.1016/j.wneu.2016.10.056

[39] Fan, G., et al. (2015) Significant Improvement of Puncture Accuracy and Fluoroscopy Reduction in Percutaneous Transforaminal Endoscopic Discectomy with Novel Lumbar Location System: Preliminary Report of Prospective Hello Study. Medicine, 94, e2189. https://doi.org/10.1097/MD.0000000000002189 


\section{Abbreviation}

$\mathrm{LDH}=$ lumbar disc herniation

PELS $=$ Percutaneous endoscopic lumbar surgery

PELD = Percutaneous endoscopic lumbar discectomy

PTELD = Percutaneous transforaminal endoscopic lumbar discectomy

IL-PELD = Interlaminar percutaneous endoscopic lumbar discectomy

TF-PELD = Transforaminal Percutaneous endoscopic lumbar discectomy

MED = Micro endoscopic discectomy

OLD = open lumbar discectomy

ODI $=$ Oswestry Disable Index

VAS $=$ Visual Analog Scale

YESS = Yeung Endoscopic spinal surgery

TESSYS $=$ Transforaminal endoscopic spine surgery system

Submit or recommend next manuscript to SCIRP and we will provide best service for you:

Accepting pre-submission inquiries through Email, Facebook, LinkedIn, Twitter, etc. A wide selection of journals (inclusive of 9 subjects, more than 200 journals)

Providing 24-hour high-quality service

User-friendly online submission system

Fair and swift peer-review system

Efficient typesetting and proofreading procedure

Display of the result of downloads and visits, as well as the number of cited articles

Maximum dissemination of your research work

Submit your manuscript at: http://papersubmission.scirp.org/

Or contact ojo@scirp.org 